\title{
A VIOLÊNCIA POLICIAL EM PÁGINAS DE REDES VIRTUAIS: IMPACTOS DAS NOTÍCIAS FALSAS NA OPINIÃO PÚBLICA
}

Luís Antônio Francisco de Souza

\begin{abstract}
Bacharel em Ciências Sociais. Possui o Doutorado (1998) em Sociologia na Universidade de São Paulo, com Estágio Sanduíche na Universidade de Toronto, Canadá (1995-1996), sob supervisão de Robert W. Shirley. Pesquisador na área de História da Polícia Civil, Processo Criminal, Violência Policial, Controle Externo sobre a Polícia, Políticas de Segurança Pública, Políticas Locais de Segurança, Violência e Direitos Humanos. É Livre-Docente na Universidade Estadual Paulista Júlio de Mesquita Filho - UNESP, Campus de Marília, atuando nos cursos de Graduação em Ciências Sociais e no curso de Pós-Graduação em Ciências Sociais, no nível de mestrado e de doutorado, tendo orientado várias dissertações de mestrado, teses de doutorado e supervisões de pós-doutorado.

E-mail:lafraso@usp.br
\end{abstract}

Luís Fernando de Castro Vascon

Bacharel em Ciências Sociais, com ênfase em Sociologia. Participa do GESP - Grupo de Estudos em Segurança Pública orientado pelo Professor Doutor Luis Antônio Francisco de Souza. Atua em conjunto ao programa do Núcleo de Ensino da Unesp de Marília, promovendo a utilização de tecnologias da informação e comunicação no ensino de sociologia.E-mail: luis.vascon@live.com.

\section{RESUMO}

A ascensão da internet, sobretudo das redes sociais virtuais, representa um marco da história moderna, modificando e reestruturando padrões de sociabilidade. Dentro das supracitadas redes sociais, observa-se uma preocupação por parte dos pesquisadores das humanidades sobre a propagação de notícias falsas, por conta da rápida disseminação em massa possibilitada pela internet. Neste contexto, o presente artigo explora esta discussão a partir da pesquisa "Construção social da realidade a partir das páginas 'Apoio policial' e 'Eu nasci pra ser polícia' no Facebook", levantando a hipótese de existência de uma associação entre notícias falsas propagadas em páginas ligadas à atuação das polícias no Brasil com os altos índices de violência policial registrados em dados oficiais. Para tal formulação, o artigo aborda primeiramente a metodologia empregada na obtenção de informações, além da contextualização sobre a violência policial no Brasil, e posteriormente apresenta os resultados coletados na pesquisa, 
permitindo deste modo uma leitura da relação entre os fenômenos estudados.

PALAVRAS-CHAVE: Notícias Falsas. Redes Sociais Virtuais. Violência Policial.

\title{
POLITICAL VIOLENCE ON PAGES OF VIRTUAL NETWORKS: IMPACTS OF FALSE NEWS IN THE PUBLIC OPINION
}

\begin{abstract}
The rise of the internet, especially virtual social networks, represents a milestone in modern history, modifying and restructuring sociability patterns. Within the aforementioned social networks, there is a concern on the part of researchers of the humanities about the propagation of false news, due to the rapid mass dissemination made possible by the internet. In this context, this article explores this discussion from the research "Social construction of reality from the pages "Apoio policial" and "Eu nasci pra ser policia" on Facebook, raising the hypothesis of an association between false news propagated The article first deals with the methodology used to obtain information, as well as the contextualization of police violence in Brazil, and, later on, it presents the results of the study of police violence in Brazil. the results collected in the research, thus allowing a reading of the relationship between the studied phenomena.
\end{abstract}

KEYWORDS: Fake News. Social Networks. Police Violence.

\section{INTRODUÇÃO}

Atualmente diversos pensadores se propuseram a compreender os efeitos da globalização na sociedade, tal discussão ganhou notoriedade sobretudo a partir da década de 1980. Entretanto, o sociólogo Anthony Giddens ${ }^{1}$ alerta que a pauta sobre o tema caminhou em grande medida para os aspectos econômicos, divergindo os autores entre críticos e céticos da globalização. Giddens afirma que os impactos deste fenômeno estão para além do econômico, sobretudo no que tange ao social (GIDDENS, 2011).

Não acredito, porém, que nem os céticos nem os radicais tenham compreendido corretamente nem o que é ela, nem suas implicações para nós. Ambos os grupos vêem o fenômeno quase exclusivamente em termos econômicos. Isso é um erro! A globalização é política, tecnológica e cultural, tanto quanto econômica. (GIDDENS, 2011, p. 21).

Neste contexto relatado pelo sociólogo inglês, a internet emerge como outro fenômeno correlato a globalização, derrubando ainda mais as fronteiras físicas, e permitindo que as pessoas transpassem suas redes de sociabilidade local, adentrando ao patamar global 
(CASTELLS, 2000). A internet contribuiu para que os indivíduos ampliassem seus poderes de comunicação, permitindo o contato oral ou visual com alguém do outro lado do mundo ao toque de um botão. Deste modo, a partir desta conjuntura, investigar a articulação entre o real e o virtual é de suma importância para a compreensão do fenômeno e seus efeitos na sociedade.

Sendo assim, o presente artigo contempla resultados referentes à pesquisa intitulada: “Construção social da realidade a partir das páginas “Apoio policial” e "Eu nasci pra ser polícia" no Facebook" realizada no ano de 2017. Dentre os objetivos do estudo, procurou-se compreender a hipótese de uma articulação de utilização de notícias falsas em páginas não oficiais ligadas a atuação das polícias no Brasil com a cultura de violência policial, explicitada através de dados oficiais. Primeiramente será exposto os métodos utilizados na obtenção de informações e coleta de dados, posteriormente é abordado a discussão em torno da violência policial no Brasil, seguido dos resultados referente a pesquisa e as considerações finais sobre a validade da hipótese construída.

\section{MÉTODOS UTILIZADOS NA PESQUISA}

Para a escolha das páginas a serem analisadas, foi realizada uma coleta de dados por meio da ferramenta $N_{e t v i z z}{ }^{2}$, da qual foram recuperadas 6.629 páginas $^{3}$ que se correlacionam a atuação das polícias no Brasil. A partir destas informações, com o desígnio de atender aos objetivos, foi adotada uma perspectiva exploratória das informações, e com um tratamento qualitativo no manuseio dos dados de fonte documental. Adiante, foram selecionadas duas páginas com a maior quantidade numérica na métrica Talking About Count (Pessoas Falando Sobre Isso), ou seja, as páginas de temática policial com a maior interação no Facebook. A seleção das páginas teve o propósito de servir como um modelo referencial de análise. Outro elemento em consideração na escolha das páginas foi à seleção de páginas não oficiais. Esse fator foi levado em consideração, pois as postagens em páginas não oficiais apresentam uma maior abertura de expressão.

Devido ao grande número de dados contidos nas páginas (levando em consideração as postagens, comentários, reações e compartilhamentos) optou-se por realizar um mapeamento de postagens durante o ano 2017. A escolha das publicações foi realizada intencionalmente, portanto, foram analisadas apenas as postagens mais relevantes para o objetivo da pesquisa.

Após a coleta de dados, as informações foram investigadas a fim de verificar a hipótese de relação entre violência policial e Fake News em páginas específicas do Facebook, conforme demonstrada nos resultados. Contudo, antes de adentrar nas informações obtidas pela pesquisa, é importante destacar o cenário da violência policial no Brasil 


\section{VIOLÊNCIA POLICIAL: UM FENÔMENO ATUAL}

O debate em torno da violência exercida pela polícia no Brasil é amplo, entretanto, as pesquisas que se propuseram a estudar o tema se depararam pela dificuldade por conta dos dados oficias, ou pelo difícil acesso ao "mundo" policial. Ao abordamos a questão da violência executada pela polícia, devemos incialmente contextualizar a violência no Brasil como um todo. O $11^{\circ}$ Anuário Brasileiro de Segurança Pública ${ }^{4}$ demonstrou que no ano de 2016, o Brasil registrou o maior número de mortes violentas comparada com os dez anos anteriores (FBSP, 2017), conforme demonstrado no Gráfico 1.

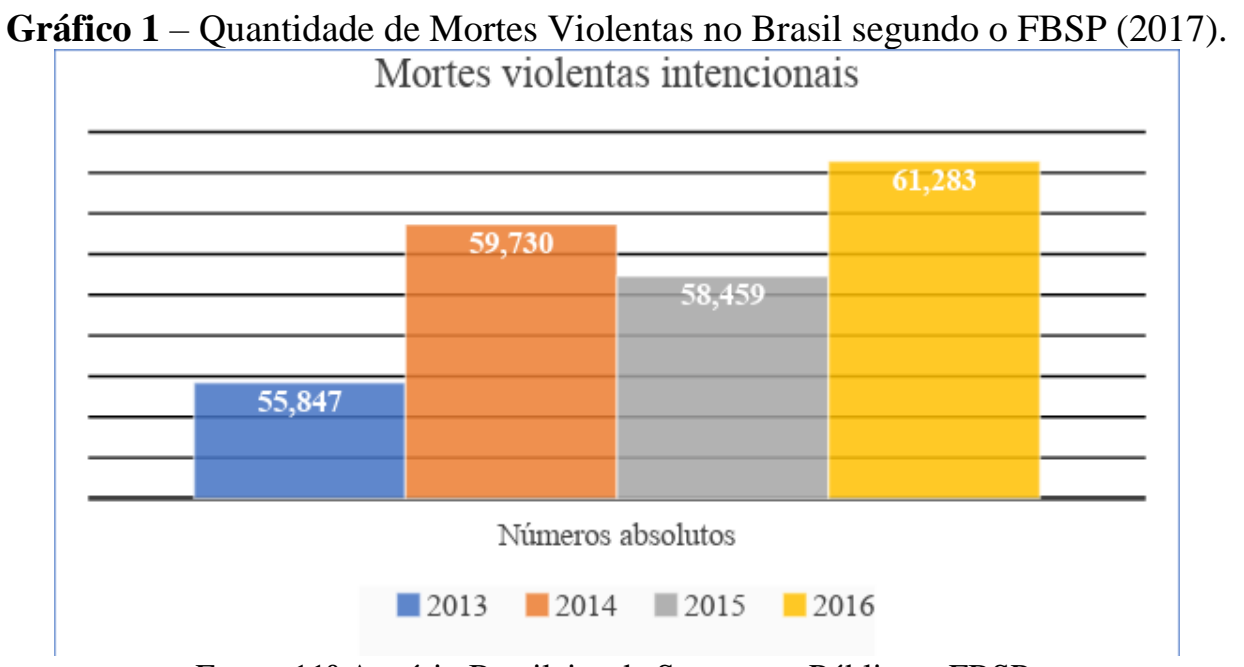

Fonte: $11^{\circ}$ Anuário Brasileiro de Segurança Pública - FBSP.

Os dados divulgados pelo Fórum Brasileiro de Segurança Pública (FBSP), demonstram que as mortes violentas no Brasil em 2016 cresceram 3,8\% em comparação com o ano de 2015 (FBSP, 2017). Outro dado importante refere-se aos índices de latrocínio, homicídio doloso, lesão corporal seguida de morte, vitimização e letalidade da polícia, havendo um aumento expressivo em relação aos anos anteriores. Quando analisados os dados sobre a violência aplicados às mortes em decorrências de ações policiais (civil e militar), observa-se que houve um aumento de 25,8\% entre os anos de 2015 a 2016. Dentre as mortes divulgadas no relatório, nota-se que 76,2\% das vítimas eram negros, e 81,8\% tinham entre 12 e 29 anos de idade.

No estado de São Paulo, de acordo com dados oficiais divulgados pela Secretaria de Segurança Pública (SSP/SP), o número de pessoas mortas pela polícia militar estadual no primeiro semestre de 2017 é o maior em dezessete anos. Segundo os dados proporcionais da secretaria, a cada policial morto em serviço, a polícia mata 36,88 pessoas (maior taxa desde 2001). Destaca-se o fato de que das 459 pessoas assassinadas pela força de segurança estadual 
no primeiro semestre de 2017, 127 foram executadas por policiais fora do horário de serviço (SSP/SP, 2017).

Gráfico 2 - Número de pessoas mortas pela polícia no $1^{\circ}$ semestre no Estado de São Paulo.

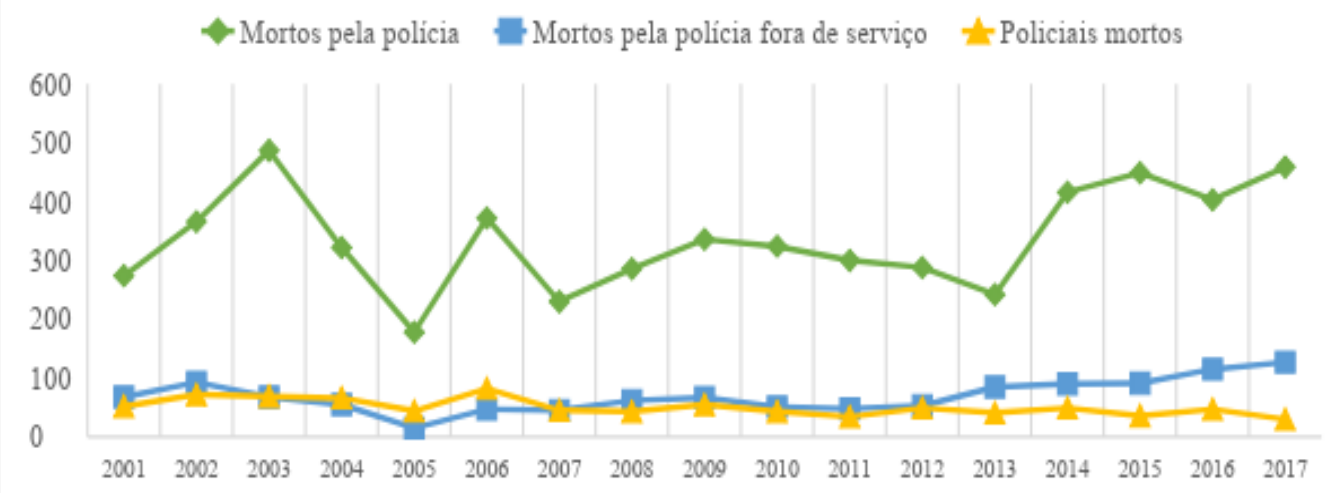

Fonte: SSP/SP - Secretaria da Segurança Pública de São Paulo (SSP/SP, 2017).

Por meio destes dados, compreende-se que a relação entre a polícia e a violência através dos índices divulgados é intrínseca. Segundo Briceño-León, Carneiro e Cruz, as ações extrajudiciais cometidas por agentes de segurança pública, tais como as ações violentas, possuem um respaldo por parte da população, fazendo com que os policiais atendam aos anseios da comunidade e não à lei ${ }^{5}$ (BRICEÑO-LÉON; CARNEIRO; CRUZ, 1999).

Neste aspecto, as redes sociais virtuais podem incentivar as ações agressivas e abusivas cometidas por agentes das forças policiais. Nas páginas pesquisadas, foi constatado que a rede social situa-se como um espaço nutrido de hostilidades exercidas pelas polícias. Dentre as postagens, destaca-se a noção de combate da violência por meio da violência, como observado em uma publicação da página "Apoio Policial" com os dizeres: "O cidadão de bem jamais usa a expressão VIOLENCIA POLICIAL. CONTRA MARGINAL não se pode enfrentar bandidos com flores, policiais façam o que deve ser feito. (sic $)^{6}$ ". A publicação supracitada expõe que a violência empreendida pela polícia, quando aplicado ao "marginal", é per si justificada. Isso fica evidenciado por meio da sentença: "Policiais façam o que deve ser feito". A preposição afirmada na publicação evidencia o paradoxo do combate da violência por meio da violência.

As frases curtas, sem discussão e imagens chamativas colaboram para um alto índice de reações, quase que a totalidade como positiva, contribuindo deste modo, para uma formação de opinião dos usuários baseada numa maior quantidade de aceitação do meio (quantidade de reações, comentários e compartilhamentos) do que em opiniões pautadas em argumentos sólidos e consistentes. 
Outro modo de disseminação e fundamentação da violência é através de publicações que utilizam o recurso da ironia e do humor. Em publicação de 10 de dezembro de 2017, a página "Eu nasci pra ser policia" utiliza uma imagem acompanhada de texto como material de afirmação da violência.

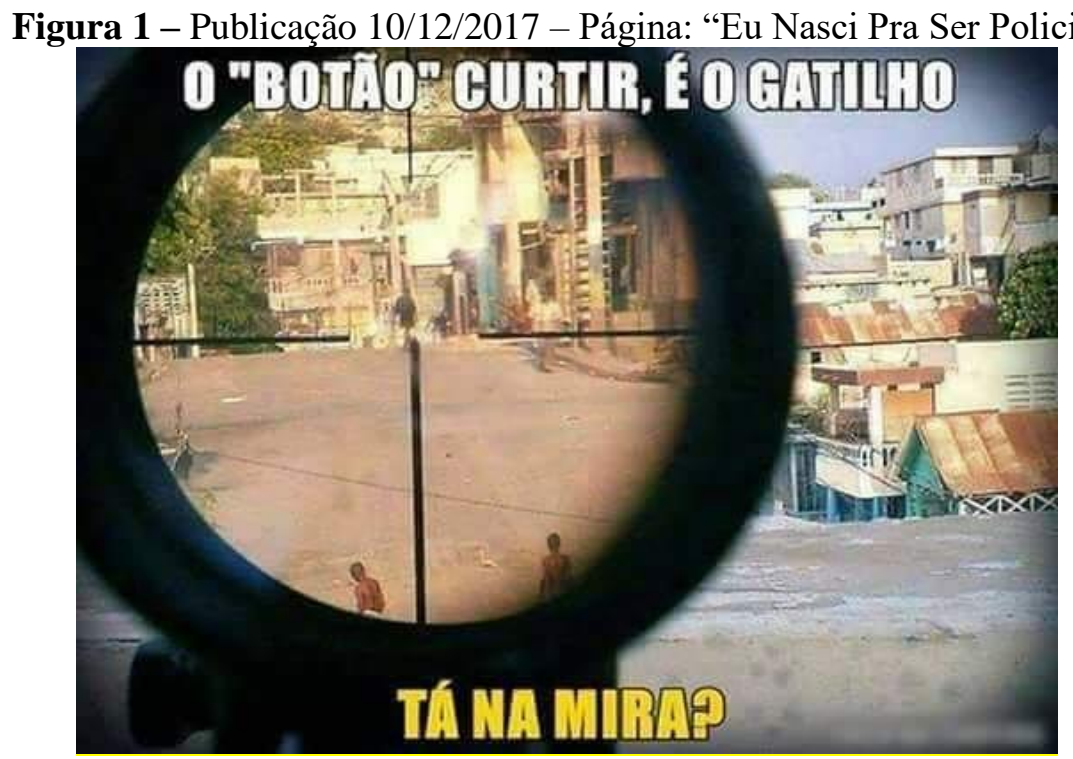

Fonte:https://www.facebook.com/eunascipraserpolicia/photos/a.282129561821118/1781516598549066/?type=3\&t heater

A postagem da page "Eu nasci pra ser policia", faz uso da ironia para defender a aplicação de violência e da força como forma de alcance da paz. Destaca-se que este tipo de publicação alcança grandes níveis de engajamento na rede.

\section{RESULTADOS}

No que tange à exemplificação de notícias falsas utilizadas nas páginas com teor policial, observamos dois tipos característicos de publicações. Na Tabela 1 é exposta uma publicação da página "Apoio Policial", onde é apresentada a captura de uma imagem referente ao canal de notícias Globo News. De acordo com a legenda que acompanha a imagem e os discursos produzidos nos comentários, observamos que o sentido da publicação foi de defesa pelo aumento de prisões preventivas, frente aos dados expostos, conforme observado a seguir:

Tabela 1 - Publicação do dia 07/06/2017 - Página: “Apoio Policial”.

\begin{tabular}{|c|c|}
\hline Data & $07 / 06 / 2017$ \\
\hline Legenda $^{7}$ & $\begin{array}{c}\text { É pra isso aí que serve as audiências de custódia. Pra soltar bandido. Se onde vc } \\
\text { mora está violento, já sabe quem culpar. Só em SP, 90\% dos marginais são } \\
\text { soltos.. é apenas 10\% fica guardado... É a polícia enxuga gelo todos os dias... } \\
\text { (sic) }\end{array}$ \\
\hline
\end{tabular}




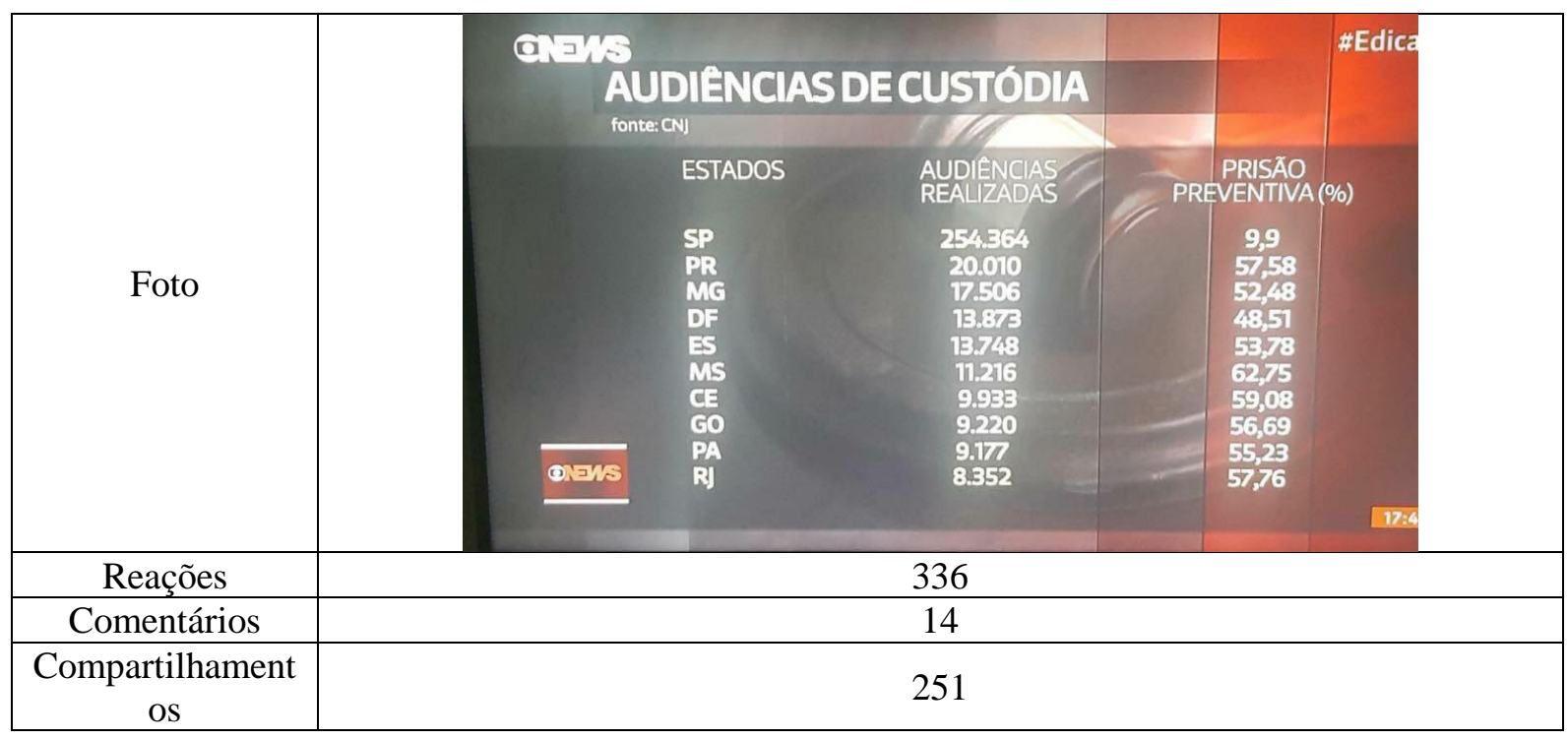

Fonte:https://www.facebook.com/fanpageapoiopolicial/photos/a.411381455564387.83314.411379318897\%203 4/1351306684905188/?type=3\&theater

A publicação em questão argumenta fora de contexto que o estado de São Paulo realizou 254.364 audiências de custódia e destas, 9,9\% culminaram em prisões preventivas. O que chama a atenção para a publicação é a ausência do período analisado. Entretanto, a publicação ganha a aparência de verdadeira devido a uma construção simbólica ligada ao logotipo da emissora de televisão. Dentre os comentários da publicação, segue alguns destaques:

Tabela 1 - Comentários Publicação 07/12/2018 - "Apoio Policial”.

Começa a matar

Dai resolve

Não lota o tribunal e usa o meliante de adubo (sic)

Não é de se espantar o fato do povo estar fazendo justiça com as próprias mãos! (sic)

olha isso de $100 \%$ dos presos $90 \%$ sao soltos no dia do julgamento ridículo (sic)

Fonte:https://www.facebook.com/fanpageapoiopolicial/photos/a.411381455564387.83314.411379318897 34/1351306684905188/?Type=3\&theater

Contudo, ao analisarmos os dados oficiais divulgados por meio do site da CNJ Conselho Nacional de Justiça (o mesmo utilizado como fonte da publicação) (CNJ, 2017), os números apresentam uma grande disparidade em comparação a informação veiculada na página “Apoio policial", como demonstrado na Gráfico 3:

Gráfico 3 - Audiência de Custódia em Números em São Paulo - Conselho Nacional de Justiça (CNJ, 2017). 
56.682 Audiêcias de Custódia realizadas

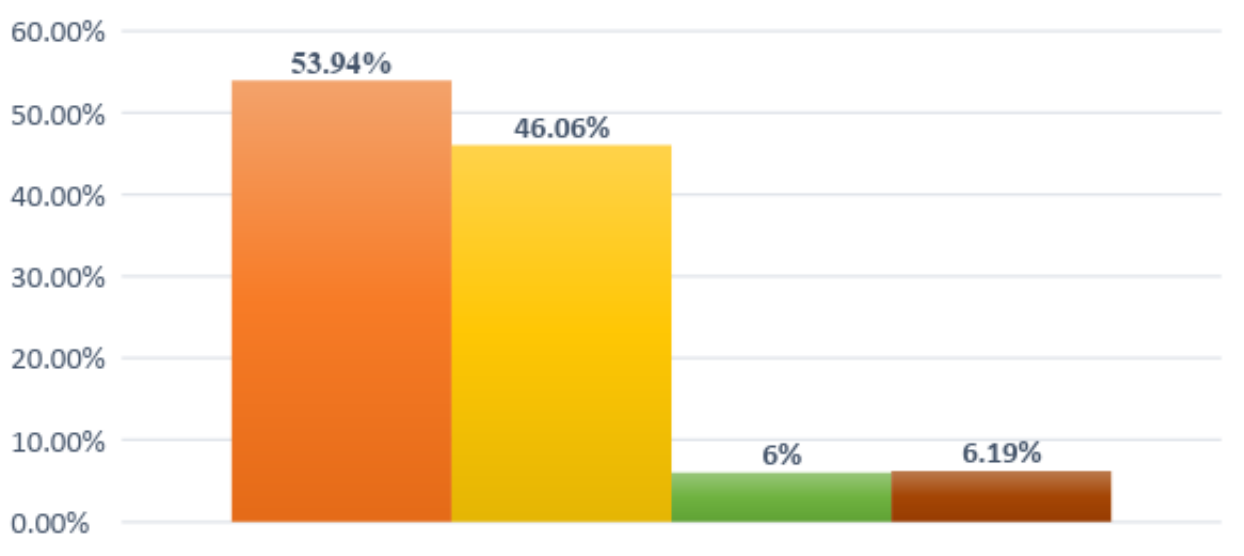

Prisão preventiva

Liberdade provisória

Alegação de violência no ato da prisão

Encaminhamento para o serviço social

Fonte: http://www.cnj.jus.br/sistema-carcerario-e-execucao-penal/audiencia-de-custodia/mapa-da-implantacao-daaudiencia-de-custodia-no-brasil. Período de 24/02/2015 a 30/06/2017. (CNJ, 2017)

Portanto, através da comparação com dados oficias, podemos caracterizar a postagem expressa na Tabela 1 como uma publicação de transmissão de notícia falsa, descaracterizando e deixando fora de contexto a notícia original veiculado na emissora Globo News. Sobre os comentários, fica evidente a indução da publicação de encontro com os valores destacado na página. Além das reafirmações da postagem como verdadeira, observam-se consequências como a incitação à violência, expressa nos comentários "Começa a matar. Aí resolve" e "justiça pelas próprias mãos". Este tipo de indução, apesar de ser realizado virtualmente, pode contribuir para o incentivo da violência no plano da realidade objetiva, como os casos de linchamento.

A pesquisa intitulada "Monitoramento das graves violações aos direitos humanos" realizado pelo NEV - Núcleo de Estudos da Violência - Universidade de São Paulo, demonstrou que o Brasil é o país com os maiores números de casos de linchamento no mundo. Segundo a pesquisa, entre 1980 a 2006 o Brasil registrou 1179 casos de linchamento (NEV, 2016). Outro estudo realizado pelo sociólogo José de Souza Martins, explicitado no livro "Linchamentos: A Justiça Popular do Brasil" analisou um período de 60 anos, onde se observou que 2.579 pessoas foram alcançadas por linchamentos, dentre as quais apenas 1.150 $(44,6 \%)$ foram resgatadas; as demais, 1.221 pessoas $(47,3 \%)$, foram agredidas e mortas pela população (MARTINS, 2015).

Entretanto, nas páginas observadas, a cultura da violência extrapola a ideia de justiça pelas próprias mãos (como nos linchamentos) e se alinha ao pensamento de violência 
justificada pelo aparelho de segurança do Estado. Neste aspecto, ressalta-se a hipótese de utilização de notícias falsas como estímulo na construção de uma cultura, muitas vezes marcadas pelo fomento de violência, conforme também destacada na Tabela 3:

Tabela 3 - Publicação do dia 26/04/2017 - Página: "Eu Nasci Pra Ser Policia".

\begin{tabular}{|c|c|c|}
\hline Data & $\begin{array}{c}\text { 26/04/2017 } \\
\text { Legenda } \\
\text { rebateu na cara dele, voltou a bater no pneu, e etc... Parecia } \\
\text { campeonato de ping pong kkkkk...(sic) }\end{array}$ \\
\hline Jovem joga pedra na viatura, a pedra atinge o \\
pneu volta e acerta seu rosto ....segundo \\
depoimento dos policias
\end{tabular}

Fonte:https://www.facebook.com/eunascipraserpolicia/photos/a.282129561821118.75200.281725565194851/1 $533175976716464 /$ ?type $=3 \&$ theater

Neste exemplo de postagem, a página "Eu nasci pra ser policia" demonstra uma segunda característica de notícia falsa, utilizando uma imagem que não pode ser comprovada, e atribuindo uma descrição com o recurso da ironia. A priori, o sentido da publicação é atrelar o uso da violência física como instrumento de correção com um tipo de postagem de cunho humorístico. De acordo com a maioria dos comentários, a ação da polícia foi correta e o emprego da força física foi necessário. Também é possível observar a incitação de ódio e violência neste tipo de publicação. A junção entre humor, ironia e violência faz com que os seguidores da página se tornem mais seguros de afirmarem: "devia per acertado era na fonte!!!" ou "Deveria ter matado", conforme demonstrado na Tabela 4: 
Tabela 2 - Comentários Publicação 26/04/2017 - Página: "Eu Nasci Pra Ser Policia".

\begin{tabular}{|c|}
\hline Ele é apenas mais uma vítima da sociedade capitalista. SQN! (sic) \\
\hline $\begin{array}{c}\text { Graças a Deus não acertou nenhum policial, devia per acertado era na fonte!!! } \\
\text { (sic) }\end{array}$ \\
\hline $\begin{array}{c}\text { Se os pais dele tivessem ensinado que não se pode jogar pedras nas pessoas isso } \\
\text { não aconteceria , vai estudar ou trabalhar (sic) }\end{array}$ \\
\hline Deveria ter matado... (sic) \\
\hline (nome) por isso eu amo a polícia (sic)
\end{tabular}

Fonte:https://www.facebook.com/Eunascipraserpolicia/photos/a.282129561821118.75200.281725565194851/1 $533175976716464 /$ ? Type $=3 \&$ theater

É possível verificar por meio de publicações, comentários e reações que as páginas analisadas estão ligadas a cultura de violência que perpassa as instituições policiais no Brasil. A violência expressada pelos seguidores e administradores da página está em sintonia, tanto em relação aos índices de violência policial no Brasil relatado anteriormente, como na aceitação da violência por uma grande parcela da população brasileira, conforme os dados coletados pelo Datafolha a pedido do Fórum Brasileiro de Segurança Pública e publicados no $10^{\circ}$ Anuário Brasileiro de Segurança Pública, onde se consta que 57\% da população brasileira acreditam que "bandido bom é bandido morto" (FBSP, 2016).

\section{CONSIDERAÇÕES FINAIS}

O presente estudo apresentou a hipótese de que as notícias falsas publicadas em páginas com teor policial podem contribuir para o avanço da cultura de violência que perpassa as forças policiais do estado. Deste modo, este artigo não tem a pretensão de realizar nenhuma conclusão absoluta e final sobres o tema; o que não inibe de chegarmos a algumas constatações e construirmos uma linha de pensamento que dê conta de entendermos as estruturas e processos dos fenômenos expostos aqui.

Nota-se que a confiabilidade das notícias ou critérios para contextualizar os fatos não é uma exigência dos administradores das páginas, sendo primordial a inserção de informações e arquivos multimídia chamativos, com discursos inflados. Como nos exemplos destacados anteriormente, o mais importante é a interação através das reações e compartilhamentos. A publicação se torna verdadeira à medida que seu engajamento é maior. É fato que este tipo de legitimação também ocorre na realidade cotidiana ${ }^{8}$. Entretanto, no ciberespaço $^{9}$ a legitimação por meio das notícias falsas ocorre a partir da crença pessoal, indicando que o que separa a verdade de uma mentira é a quantidade de pessoas que compactuam de um mesmo pensamento. 
Portanto, a noção do que é verdade numa postagem é parte de uma construção identitária $^{10}$ diferenciando-se subjetivamente de indivíduo para outro e seus efeitos podem contribuir para a formação de uma identidade cultural, favorecendo no caso das páginas estudadas, para os altos índices de violência policial.

Concluímos que o campo da virtualidade e segurança públicas é imenso, com diversos conteúdos a serem estudados. A proposta de compreender a correspondência das Fake News em páginas policiais no Facebook com a cultura da violência se mostrou impactante. Pode-se inferir que nas páginas estudadas, a hipótese de relação entre notícias falsas e violência policial é verdadeira, expressa sobretudo pela defesa de uma atuação agressiva pela polícia, evidenciado nas publicações e comentários como forma de repúdio as notícias veiculadas (mesmo algumas sendo falsas ou fora de contextos). Entretanto, devido ao pequeno recorte utilizado na pesquisa, não é possível constatar a relação direta entre todas as páginas com teor policial, Fake News e violência, apesar do estudo possibilitar uma compreensão mais aprofundada sobre o tema. Sendo assim, é concebível que a metodologia aplicada ao campo virtual pode materializar a compreensão não somente da temática policial, como diversas outras.

\footnotetext{
NOTAS

${ }^{1}$ Sociólogo Britânico, autor da teoria da estruturação. Giddens foi diretor da London School of Economics, e autor de obras como Mundo em Descontrole, Sociologia e Modernização Reflexiva.

${ }^{2}$ O Netvizz é uma ferramenta que extrai dados de diferentes seções da plataforma do Facebook em determinados grupos e páginas para fins de pesquisa (RIEDER, 2013).

3 A primeira ação em relação à extração das informações foi definir todos os termos que abrangem a temática policial. Devido aos escassos estudos utilizando esta metodologia, foi necessário elaborar termos que mais se associassem à temática. Os termos de busca utilizados foram: 1) Arma; 2) Bandido; 3) Batalhão; 4) Bope; 5) Caveira; 6) Farda; 7) Força Tática; 8) Getam; 9) Militar; 10) Operações Especiais; 11) Polícia; 12) Rocam; 13) Rota e 14) Tropa.

4 Anuário desenvolvido pelo FBSP - Fórum Brasileiro de Segurança Pública. Acessível em: http://www.forumseguranca.org.br/wp-content/uploads/2019/01/ANUARIO_11_2017.pdf

${ }^{5}$ A pesquisa foi realizada a partir do apoio da população as ações extrajudiciais de policiais no Brasil, El Salvador e Venezuela.

${ }^{6} \mathrm{~A}$ publicação pode ser acessada do link: https://www.facebook.com/FanpageApoioPolicial/photos/a.411381455564387.83314.411379318897934/1473322 $272703628 /$ type $=3 \&$ theater

7 As legendas são transcrições dos comentários originais (publicados por usuários das páginas estudadas), não havendo modificações gramaticais.

${ }^{8}$ A realidade cotidiana é parte do conceito de Construção Social da Realidade, elaborado por Peter Berger e Thomas Luckmann. A realidade cotidiana refere-se a junção das realidades objetivas e subjetivas. (BERGER; LUCKMANN, 1990)

${ }^{9}$ Conceito cunhado por Pierre Levy (LÉVY, 2011).

${ }^{10}$ Conforme as preposições de P. Berger e T. Luckmann (BERGER; LUCKMANN, 1990).
} 


\section{REFERÊNCIAS BIBLIOGRÁFICAS}

BERGER, Peter L.; LUCKMANN, Thomas. A Construção Social da Realidade. 8. ed. Petrópolis: Editora Vozes, 1990.

BRICEÑO-LÉON, R.; CARNEIRO, L. P.; CRUZ, J. M. O apoio dos cidadãos à ação extrajudicial da polícia no Brasil, em El Salvador e na Venezuela. Cidadania, justiça e violência, p. 117127, 1999.

CASTELLS, Manuel. A Sociedade em Rede: A era da informação: economia, sociedade e cultura. São Paulo: Paz e Terra, 2000.

CNJ, Conselho Nacional de Justiça. Dados Estatísticos / Mapa de Implantação: São Paulo. Disponível em: <http://www.cnj.jus.br/sistemacarcerario-e-execucao-penal/audienciade-custodia/mapa-da-implantacao-daaudiencia-de-custodia-no-brasil>.

Acesso em: 10 jan. 2019.

FBSP, Fórum Brasileiro de Segurança Pública. Anuário Brasileiro de Segurança Pública de 2016. Brasil.
Segurança Pública., 2016.

GIDDENS, Anthony. Mundo em Descontrole. Rio de Janeiro: Editora Record, 2011. v. 8.

LÉVY, Pierre. O que é o virtual? 2. ed. São Paulo: Editora 34, 2011.

MARTINS, José de Souza. Linchamentos - A Justiça Popular No Brasil. São Paulo: Editora Contexto, 2015.

NEV, Núcleo de Estudos da Violência Universidade de São Paulo. Monitoramento das graves violações aos direitos humanos. Disponível em: <http://nevusp.org/blog/2015/04/24/ban co-de-dados-da-imprensa-sobre-asgraves-violacoes-de-direitos-humanosdados-por-violacao-linchamento/>. Acesso em: 2 dez. 2017.

SSP/SP, Secretaria de Segurança Pública de São Paulo. Relatórios e Estudos. Disponível em: <http://www.ssp.sp.gov.br/Estatistica/E studos.aspx >. Acesso em: 12 jan. 2019.

SOUZA., L.A.F.; VASCON, L.F.C. A Violência Policial em Páginas de Redes Virtuais: Impactos das Notícias Falsas na Opinião Pública. Complexitas - Rev. Fil. Tem. Belém, v. 3, n.1, p. 16-27, jan./jun., 2018.

Disponível em:<http://www.periodicos.ufpa.br/index.php/complexitas/article/view/6624>. Acesso em: 20 de fevereiro de 2019. 